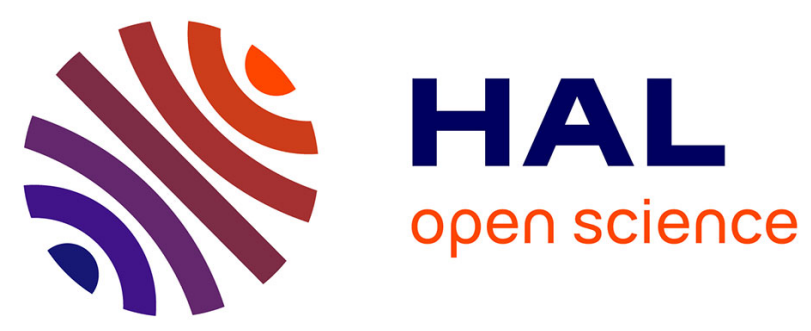

\title{
Adverse effects induced by chronic gamma irradiation in progeny of adult fish not affecting parental reproductive performance
}

Noémie Guirandy, Béatrice Gagnaire, Sandrine Frelon, Thomas Munch, Nicolas Dubourg, Virginie Camilleri, Isabelle Cavalie, Magali Floriani, Caroline Arcanjo, Sophia Murat El Houdigui, et al.

\section{To cite this version:}

Noémie Guirandy, Béatrice Gagnaire, Sandrine Frelon, Thomas Munch, Nicolas Dubourg, et al.. Adverse effects induced by chronic gamma irradiation in progeny of adult fish not affecting parental reproductive performance. Environmental Toxicology and Chemistry, 2019, 38 (11), pp.2556-2567. 10.1002/etc.4562 . hal-02324157

\section{HAL Id: hal-02324157 \\ https://hal.science/hal-02324157}

Submitted on 7 Jul 2020

HAL is a multi-disciplinary open access archive for the deposit and dissemination of scientific research documents, whether they are published or not. The documents may come from teaching and research institutions in France or abroad, or from public or private research centers.
L'archive ouverte pluridisciplinaire HAL, est destinée au dépôt et à la diffusion de documents scientifiques de niveau recherche, publiés ou non, émanant des établissements d'enseignement et de recherche français ou étrangers, des laboratoires publics ou privés. 
1 Référence :

2 GUIRANDY Noemie, GAGNAIRE Beatrice, FRELON Sandrine, MUNCH Thomas,

3 DUBOURG Nicolas, CAMILLERI Virginie, CAVALIE Isabelle, FLORIANI Magali,

4 ARCANJO Caroline, MURAT EL HOUDIGUI Sophia, ARMANT Olivier, ADAM-

5 GUILLERMIN Christelle, GONZALEZ Patrice, SIMON Olivier

6 Adverse effects induced by chronic gamma irradiation in progeny of adult fish not

7 affecting parental reproductive performance

8 Environ. Toxicol. Chem., 38, 11 (John Wiley \& Sons Ltd 2019) 2556-2567 |

9 10.1002/etc.4562 (ACL)

Auteurs dans l'ordre de la publication:

1, GUIRANDY, Noemie

14 2, GAGNAIRE, Beatrice Institut de radioprotection et sûreté nucléaire, PSE-ENV/SRTE/LECO, Cadarache, France 3, FRELON, Sandrine Institut de radioprotection et sûreté nucléaire, PSE-ENV/SRTE/LECO, Cadarache, France 4, MUNCH, Thomas Institut de Radioprotection et de Sûreté Nucléaire, PSE-ENV/SRTE/LECO, France 5, DUBOURG, Nicolas Institut de radioprotection et sûreté nucléaire, PSE-ENV/SRTE/LECO, Cadarache, France 6, CAMILLERI, Virginie Institut de radioprotection et sûreté nucléaire, PSE-ENV/SRTE/LECO, Cadarache, France 7, CAVALIE, Isabelle Institut de radioprotection et sûreté nucléaire, PSE-ENV/SRTE/LECO, Cadarache, France 8, FLORIANI, Magali Institut de radioprotection et sûreté nucléaire, PSE-ENV/SRTE/LECO, Cadarache, France 9, ARCANJO, Caroline Institut de Radioprotection et de Sûreté Nucléaire, PSE-ENV/SRTE/LECO, France 10, MURAT EL HOUDIGUI, Sophia Institut de radioprotection et sûreté nucléaire, PSE-ENV/SRTE/LECO, Cadarache, France 11, ARMANT, Olivier Institut de radioprotection et sûreté nucléaire, PSE-ENV/SRTE/LECO, Cadarache, France 12, ADAM-GUILLERMIN, Christelle Institut de radioprotection et sûreté nucléaire, PSE-SANTE/SDOS/LMDN, Cadarache, France 13, GONZALEZ, Patrice Université Bordeaux, UMR CNRS 5805, Avenue des Facultés - 33405 TALENCE

38 CEDEX, France 
41 Running Head: Irradiation leads to drastic effects in progeny

42 Title: Adverse effects induced by chronic gamma irradiation in progeny of adult fish not

43 affecting parental reproductive performance

44 Abstract: Multigenerational studies has become of great interest in ecotoxicology since the consequence of parental exposure to contaminants on offspring generations was established in situ or in laboratory conditions. This study mainly examined the chronic effects of external Cs-137 gamma irradiation exposure at 4 dose rates (control, $0.5,5$ and $50 \mathrm{mGy} \mathrm{h}^{-1}$ ) on adult zebrafish (F0) exposed for 10 days and its progeny (F1) exposed or unexposed for $4 / 5$ days. The main endpoints investigated included parental reproductive performance, embryo-larval survival, DNA alterations and ROS production in F0 and F1. No effects on reproductive success, fecundity or egg fertilization rate were observed. However, drastic effects were observed on $\mathrm{F} 1$ exposed to $50 \mathrm{mGy} \mathrm{h}^{-1}$, resulting in a mortality rate of $100 \%$. The drastic effects were also observed when the progeny was not irradiated. It was demonstrated that the sensitivity of the embryos was mainly due to parental irradiation. Moreover, these drastic effects induced by adult irradiation disappeared over time when $10 \mathrm{~d}$ - irradiated adults were placed in a non-irradiated condition. DNA alterations in larvae were observed for the three dose rates, and an increase of ROS production was also shown for the two lowest dose rates. This study improves our understanding of the consequences of parental exposure conditions to the progeny. Furthermore, it provides an incentive to take transmitted generational effects into account in ecological risk assessments.

Keywords: reproduction, irradiation exposure, zebrafish, risk assessment 


\section{INTRODUCTION}

Gamma radiation represents a potential health risk to biota, due to its ability to ionize molecules in tissue. Ionizing radiation is known to induce oxidative stress, DNA damage and apoptosis, which therefore constitute usual molecular markers for evaluating toxicity mechanisms(Gagnaire et al. 2015; Jaafar et al. 2013; Knowles 2002; Praveen Kumar et al. 2017; Simon et al. 2011b; Sinha et al. 2018). Significant effects in animals (fish, nematode, Daphnia) in terms of survival, reproduction and development have been observed (AdamGuillermin et al. 2012; Buisset-Goussen et al. 2014; Gagnaire et al. 2015; Knowles 2002; Parisot et al. 2015; Simon et al. 2011b). Moreover, damage effects in fish have mainly been observed for early life stages, which are considered as the most vulnerable to ionizing radiation. Embryogenesis, in addition to gametogenesis and organogenesis, can be affected by ionizing radiation due to the high rate of cell division, proliferation and differentiation (Hurem et al. 2017a; Hurem et al. 2018) and enable the consequences of irradiation to be assessed.

In terms of ecological risk assessment (ERA), endpoints on the impact on adult reproduction performance (reproductive success, fecundity, fertility) and on development of early stages (growth, survival) remain the main useful endpoints in characterising the ecological consequences of pollutants, including ionizing radiation. Radiological protection criteria are largely based on data from acute exposure experiments of adult organisms, thus information on the effects of ionizing radiation during sensitive life stages and after chronic exposure are lacking (Hurem et al. 2017a; Hurem et al. 2017b). Overall, few data are available concerning the effects of ionizing radiation in fish. The ecological screening benchmark for a generic 
ecosystem of $10 \mu \mathrm{Gy} \mathrm{h}^{-1}$ based on the $\mathrm{HDR}_{5}$ (Hazardous Dose Rate for $5 \%$ of the species) for radioactive substances was built with five $\mathrm{EDR}_{10}$ (Effect Dose Rate related to a change of $10 \%$ for a particular effect) from fish, which involved values ranging from 47 to $20,881 \mu \mathrm{Gy}$ $\mathrm{h}^{-1}$ (Garnier-Laplace et al. 2010). This generic benchmark dose rate was proposed by the European project, ERICA, for the screening of potential radiological effects (Brown et al. 2008). For freshwater and chronic $\gamma$ external exposure, applying a safety factor of 50 to the lowest $\mathrm{EDR}_{10}$ (reproductive endpoint: $516 \mu \mathrm{Gy} \mathrm{h}^{-1}$ ) led to a predicted no-effect value of 10 $\mu \mathrm{Gy} \mathrm{h}^{-1}$ (Garnier-Laplace et al. 2006). Derived consideration reference levels (DCRLs) i.e., "the dose rate band within which there is likely to be some chance of deleterious effects occurring to individuals of such type of a given type of Reference Animal and Plant (RAP)" indicate a possible reduction of reproductive success for dose rates ranging between 40 and $4,000 \mu \mathrm{Gy} \mathrm{h}^{-1}$ for trout (ICRP 2012).

Firstly, the $\mathrm{EDR}_{10}$ did not include the assessment of adult reproduction performance. Secondly, none of these fish species belong to the cyprinid family. Thirdly, the consequence of parental exposure for offspring generations have not yet been taken into account in the ERA. However, multigenerational studies have become of great interest (Buisset-Goussen et al. 2014; Hurem et al. 2017a; Lemos et al. 2017; Parisot et al. 2015). For fish, the progeny of adult zebrafish exposed to $53 \mathrm{mGy} \mathrm{h}^{-1}$ ( ${ }^{60} \mathrm{Co}$ gamma radiation) for 27 days showed a $100 \%$ mortality rate occurring at the gastrula stage (Hurem et al. 2017a). Thus, parental exposure can lead to hereditary effects in offspring, probably due to epigenetic mechanisms (Herráez et al. 2017; Hurem et al. 2017a; Lemos et al. 2017). 
As fish are known to be the most radiosensitive organisms among the poikilothermic aquatic animals (Garnier-Laplace et al. 2006), zebrafish, or Danio rerio, were chosen in the

111 present research as a cyprinid model for assessing gamma radiation effects on reproduction

112 performance and larval development. Zebrafish have been widely used for examining effects

113 of ionizing radiation (Choi et al. 2010; Choi et al. 2015; Gagnaire et al. 2015; Hurem et al.

114 2017a; Hurem et al. 2017b; McAleer et al. 2005; Ng et al. 2017; Simon et al. 2011b; Yum et al. 2010) in addition to transgenerational effects (Hurem et al. 2017a; Kamstra et al. 2018). Indeed, breeding success, high fecundity and rapid development are the main advantages of this model in performing multigenerational studies (Lawrence 2007; Simon et al. 2014).

In this study, adult zebrafish were exposed to four dose rates $\left(0,0.5,5\right.$ and $50 \mathrm{mGy} \mathrm{h}^{-1}$,

${ }^{137}$ Cs gamma radiation) over 10 days. The dose rates were higher than those in "hot spots" measured in freshwater ecosystems around Chernobyl $\left(<0.2 \mathrm{mGy} \mathrm{h}^{-1}\right)($ Bonzom et al. 2016;

121 Fuller et al. 2018; Lecomte-Pradines et al. 2014; Lerebours et al. 2018). Reproduction was initiated and the progeny were then exposed or not to the same dose rates over 96-120 hours. The objectives of this study were to evaluate (i) the adult reproductive performance, (ii) the

124 effects in the progeny of irradiated parents and (iii) the responses at the molecular and 125 organism level. Effects on adults were assessed by reproductive performance and genotoxicity 126 (comet assay). Effects on the progeny were assessed using the survival rate (\%) and the genotoxic and oxidative stress effects. The progeny were also placed in non-irradiated conditions (F1 recovery) over 120 hours to evaluate the impact of adult irradiation on the 129 progeny (generational effects).

Complementary objectives concerned the increase of the exposure duration on the effects

131 and the time necessary to obtain reproductive resilience: for the two lowest dose rates tested

132 (lowDR: 0.5, $5 \mathrm{mGy} \mathrm{h}^{-1}$ ), adult F0 exposure duration was increased to 24 days; for the highest 
133 dose rate (highDR: $50 \mathrm{mGy} \mathrm{h}^{-1}$ ), 10 day-irradiated adults (F0) were placed in non-irradiated

134 conditions over 63 days (F0 recovery). Adult performance, progeny survival and molecular

135 effects were also evaluated during these complementary experiments.

136 MATERIALS AND METHODS

137 Fish husbandry

138 The project (APAFIS\#15821) was authorized by the IRSN ethics committee $\mathrm{N}^{\circ} 81$ (EU

139 0520) in an application under the directive 2010/63/UE relating to animal care. The study was

140 conducted on wild-type zebrafish that were kept, reproduced and irradiated in a zebrafish

141 housing system (Zebtec Tecniplast stand Alone, Varese, Italy) with recirculating fresh water.

142 Adult fish were acclimatised over 2-3 weeks to tap water $+20 \%$ demineralized water renewed

143 daily (Aquadem, Veolia, France) $\left(\mathrm{pH}=7.4 \pm 0.2\right.$, conductivity $=398 \pm 2 \mu \mathrm{S} \mathrm{cm}^{-1}, \mathrm{~T}=28.4 \pm$

$1440.3{ }^{\circ} \mathrm{C}$ ), with a $14 \mathrm{~h}$ light $/ 10 \mathrm{~h}$ dark cycle photoperiod. The fish were fed ab libitum twice a

145 day with commercial flakes (Tetramin $®)$.

146 Adult and embryo exposure

147 Figure 1 shows the exposure duration and endpoints for the experiments. Nominal dose

148 rates were 0.5 and $5 \mathrm{mGy} \mathrm{h}^{-1}$ for the low dose experiment (lowDR) and $50 \mathrm{mGy} \mathrm{h}^{-1}$ for the

149 high dose experiment (highDR). As both experiments (lowDR and highDR) were not carried

150 out at the same time, control fish conditions were implemented for each experiment. Gamma-

151 rays were emitted from a ${ }^{137} \mathrm{Cs}$ source (444 GBq, $662 \mathrm{keV}$, IRSN-MICADO-Lab platform).

152 Dose rates were simulated using MCNP5 software and measured using thermoluminescent

153 dosimeters (Chiyoada Technologies, Japan) and the values represented between 91.1 and 
$154100.8 \%$ and between 80 and $120 \%$ of the nominal low DR and high DR values, respectively.

155 Two control conditions were kept in a separate room (60-80 $\left.\mathrm{nGy} \mathrm{h}^{-1}\right)$.

156

157

The population density of adult fish was $0.7 \mathrm{~L} \mathrm{~g}^{-1}$. For the low dose rate experiment (lowDR), 20 adult fish per condition (female: $0.66 \pm 0.13 \mathrm{~g}, \mathrm{n}=24$, male: $0.50 \pm 0.065 \mathrm{~g}$, $\mathrm{n}=11$ ) were irradiated over 10 and 24 days. For the high dose rate experiment (highDR), 24 adult fish per condition (female: $0.38 \pm 0.06 \mathrm{~g}, \mathrm{n}=6$, male: $0.40 \pm 0.07 \mathrm{~g}, \mathrm{n}=6$ ) were irradiated over 10 days. To keep the radiation exposure as long as possible, the daily control of abiotic parameters ( $\mathrm{pH}$, conductivity, Temperature), the animal welfare and the feeding process were carried out in less than one hour, five times per week. During this hour, irradiation was stopped in order to access to the tanks. Food was supplied to the fish twice a day by automatic suppliers. During the weekends, the control of these parameters was achieved through the use of cameras, allowing animal welfare to be monitored without interrupting the irradiation. The preparation of reproduction and egg collection required stopping the irradiation during four hours. After $24 \mathrm{~d}$ of exposure, the adults from lowDR were sacrificed and the gonads were collected. After $10 \mathrm{~d}$ of exposure, six adults from highDR were sacrificed and the gonads were collected. Six other adults were introduced into non-irradiation conditions (F0 Recovery).

For each reproduction event, embryos were obtained from 10 spawning genitors (i.e. replicates) for lowDR and 12 genitors (i.e. replicates) for highDR per condition. Each group, consisting of one male and one female, was placed in specific spawning aquariums to avoid egg predation in the zebrafish housing system. Adults were irradiated during reproduction. After spawning, the egg viability (3-4 hpf, hours post fertilisation) of each spawn was confirmed when the blastula stage was reached. The embryos $(2.6 \mathrm{ml} / \mathrm{egg})$ were then reintroduced into small beakers $(\varnothing=9 \mathrm{~cm})$ in the zebrafish housing system to be irradiated (at 
178 the same dose rate as the adult groups (F1 irradiated group) or without irradiation (F1

179 Recovery group) and larvae were fed starting from $5 \mathrm{dpf}$ (days post fertilisation) (artificial

180 commercial food ST-1, Aqua Schwarz GmbH). The culture medium of the embryos was the

181 same as that of the adults and $10 \%$ was replenished daily.

182 Ecologically-representative endpoints for adults

183 For the lowDR experiment, adult F0 reproductive performance ( $\mathrm{n}=10$ couples per condition)

184 was assessed after 10 and 24 days of exposure for both dose rates tested. Endpoints concerned

185 the reproductive success (number of couples that spawned), the fecundity (number of eggs per

186 female) and the egg survival rate at $3 \mathrm{hpf}$ (fertilization rate). For the highDR experiment, F0

187 reproductive performance was assessed after 10 days of irradiation $(n=12$ couples per

188 condition) and after 6,36 and 63 days in non-irradiated conditions (F0 Recovery, $\mathrm{n}=6$

189 couples) (Figure 1).

190 Ecologically-representative endpoints and oxidative stress analysis for progeny

191 For both experiments, the progeny survival rate (\%) was assessed after 24 and $48 \mathrm{~h}$ in the

192 control, irradiated and non-irradiated (recovery) conditions. Complementary experiments

193 consisted of irradiating $3 \mathrm{hpf}$-eggs at $50 \mathrm{mGy} \mathrm{h}^{-1}$ over $96 \mathrm{~h}$ (30 eggs from three spawns per

194 condition) to measure the survival rate.

195 For the lowDR experiment, two pseudo-replicates of 80 eggs originating from three spawns

196 per condition including the control, irradiated and non-irradiated conditions, were followed to

197 measure the progeny survival rate over 1,2, 10 and $22 \mathrm{~d}$. For the highDR experiment, 30 eggs

198 from six spawns of the three conditions were tracked over $5 \mathrm{~d}(120 \mathrm{~h})$. 
For the highDR experiment, photographs of $72 \mathrm{hpf-larvae} \mathrm{were} \mathrm{recorded.} \mathrm{Morphology}$

200 (whole body size, surface of yolk reserve), malformations and cardiac edema were then assessed using software (Danioscope image analysis system version 10.0, Noldus). Analyses were made on 1072 hpf-larvae per condition after $10 \mathrm{~d}$ F0 exposure (F0Irr. 10d) and after F0 recovery at 6 days (T10d+R6d) and at 36 days (T10d+R36d).

Reactive oxygen species (ROS) production was measured in F1-progeny from the lowDR experiment using a protocol adapted from Hurem et al, (2017) and Gagnaire et al., 2015. Given the high larval mortality rate, no measurements were made during the highDR experiment. ROS production was determined using the fluorescent probe $\left(2^{\prime}, 7^{\prime}-\right.$ dichlorodihydrofluorescein diacetate $\left(\mathrm{H}_{2} \mathrm{DCFDA}\right.$, Sigma-Aldrich, St. Louis, USA)) in 10 larvae per condition (larvae exposed from 3-4 hpf to 4 or 10 days originating from $10 \mathrm{~d}$-adult 210 and 24 d-adult reproduction). Through the oxidation of $\mathrm{H}_{2}$ DCFDA in dimethylsulfoxide

211 (DMSO, Sigma-Aldrich, St. Louis, USA) water by ROS (mainly $\mathrm{H}_{2} \mathrm{O}_{2}$ ) the molecule was 212 converted into 2', 7' dichlorodihydrofluorescein (DCF), which is highly fluorescent. The 213 reported wavelengths for the measurement of DCF fluorescence are $500 \mathrm{~nm}$ for excitation and $214525 \mathrm{~nm}$ for emission (TECAN Infinite M1000, Switzerland).

\section{Genotoxic effects in progeny and adult}

The genotoxic effects induced by gamma irradiation in the developmental stages $(1 \mathrm{~d}, 4$

$217 \mathrm{~d}, 10 \mathrm{~d}$ for lowDR and $1 \mathrm{~d}$ for highDR experiments) and in gonads (10 d, highDR experiment) 218 of zebrafish were evaluated using the alkaline comet assay as described in Sing et al, (1998) 219 (1988) with modifications (Simon et al. 2011a; Simon et al. 2018). After centrifugation (110 $220 \mathrm{~g}, 10 \mathrm{~min}, 8^{\circ} \mathrm{C}$, Eppendorf, 5427R, Germany), pellets were suspended in $1 \mathrm{~mL}$ of L15221 HEPES and used immediately. Cells were counted on a Malassez cell and their viability was 
assessed using trypan blue. Two hundred nucleoids per slide were analysed at $\times 400$

223 magnification under a fluorescence microscope (Nikon Eclipse E600) equipped with a 515-

$224560 \mathrm{~nm}$ excitation filter. Comet pictures were analysed using Comet IV software (Perceptive

225 Instruments). This assay was performed on three pools of ten 24-hpf eggs, on 10 individual

226 96-hpf larvae and on three pools of whole gonads per sex and per condition. The Tail Moment

227 was defined as the percentage of DNA in the tail multiplied by the length between the centre

228 of the head and tail.

229 Statistical analysis

All data are presented as means $\pm \mathrm{SD}$ with significance taken at $p<0.05$. A comparison

231 between the control and irradiation or recovery exposures was performed. Before the

232 statistical analyses, the normality and homogeneity of the variance were tested using the

233 Shapiro-Wilks and Fisher tests, respectively. The T-test and one or two ways-ANOVAs were

234 used when data were normally distributed. The non-parametric test (Kruskal-Wallis) was used

235 when data were not normally distributed.

\section{RESULTS}

237 There were no instances of adult fish mortality during the experimental periods (control, 238 low DR and high DR experiments).

239 Cumulative doses after exposure conditions

For the LowDR experiment, cumulative doses in adults ranged between 120 and 2880

241 mGy after 10 and 24 days of exposure, respectively. For the highDR experiment, the

242 cumulative dose in adults was 12 Gy (SD Table 1). For the progeny, maximal cumulative 
243 doses ranged from 264 to $2640 \mathrm{mGy}$ for the lowDR experiment and 6 Gy for the highDR 244 experiment (SD Table 1).

Adult performance (reproductive success, fecundity, total egg mumber and 3hpf-egg mortality)

For the highDR experiment, all females ( $n=12$ per condition) spawned after 10 days of exposure. For the lowDR experiment ( $\mathrm{n}=10$ per condition), reproductive success was $100 \%$ and $80 \%$ for both the irradiated conditions and control conditions, respectively.

Figure 2 shows the fecundity (number of eggs per female) after 10 days of exposure for 250 both experiments. High inter-individual variability was observed in all conditions. A 251 significant difference (Kruskal-Wallis, $\mathrm{p}=0.03$ ) was observed between $0.5 \mathrm{mGy} \mathrm{h}^{-1}$ (240 eggs $252 \pm 132)$ and control (364 eggs \pm 123 ) conditions. In the control LowDR, $43 \%$ of all spawns 253 ranged between 101 and 300 eggs and 57\% of spawns had higher than 300 eggs. At 0.5 mGy $254 \mathrm{~h}^{-1}, 20 \%$ of all spawns produced less than 100 eggs. At $5 \mathrm{mGy} \mathrm{h}^{-1}$, no significant difference in 255 fecundity (413 eggs \pm 148 ) was observed even though $89 \%$ of spawns had more than 300 256 eggs. At the high dose rate $\left(50 \mathrm{mGy} \mathrm{h}^{-1}\right)$, a change in the size of spawns was also observed, 257 with an increase in the number of spawning events $(75 \%, 9 / 12)$, providing between 101 and 258300 eggs compared to the control $(42 \%, 5 / 12)$.

259 A significant difference was observed between both control fish fecundity (lowDR: 364 eggs $260 \pm 123$ per female $(n=7)$ versus the highDR: $203 \pm 117$ eggs per female $(n=12), p=0.042$ 261 Kruskal-Wallis test) and egg quantity distribution.

262 The quality of oocytes was assessed by the survival 3hpf-progeny, indicating the number of 263 fertilized versus non-fertilized eggs. The survival rate at $3 \mathrm{hpf}$ remained high $(>89 \%)$ without 264 any significant difference between exposure conditions (SD Figure 1). Over the 50 spawns 
monitored, only two presented a survival rate of less than $80 \%$. Almost $85 \%$ of the spawns presented a survival rate of $90-100 \%$.

Reproductive success after 24 days of lowDR exposure was not impacted by irradiation; 80 , 90 and $100 \%$ of couples reproduced for the controls, 0.5 and $5 \mathrm{mGy} \mathrm{h}^{-1}$, respectively. The significant difference in fecundity previously observed after 10 days between the control and $0.5 \mathrm{mGy} \mathrm{h}^{-1}$ was not observed after $24 \mathrm{~d}$ of exposure. Fecundity was $375 \pm 102,289 \pm 138$ and $357 \pm 138$ eggs per female for the controls, 0.5 and $5 \mathrm{mGy} \mathrm{h}^{-1}$, respectively. In the controls, $37.5 \%$ of spawns contained between 101 and 300 eggs and $62.5 \%$ contained more than 301 eggs, as observed after 10 days. At $5 \mathrm{mGy} \mathrm{h}^{-1}, 75 \%$ of spawns presented more than 301 eggs, as previously observed after 10 days of exposure. The survival rate at 3 hpf-egg was close to the one measured after 10 days of adult exposure.

\section{Progeny survival and size}

Figure 3 shows F1 progeny survival rate (\%) measured at 24 and $48 \mathrm{~h}$ for all exposure conditions of both experiments. For the lowDR experiment, the survival rate was higher than $87 \%$, with no significant difference between the conditions. For the highDR experiment, a significant difference was observed between the control and larvae exposed to $50 \mathrm{mGy} \mathrm{h}^{-1}$ for $24 \mathrm{~h}(\mathrm{p}=0.02)$ and $48 \mathrm{~h}(\mathrm{p}=0.006)$. Significant differences were also observed between the control and F1 recovery conditions for both times ( $p=0.015$ and $p=0.006$ for 24 and $48 \mathrm{~h}$, respectively). Figure 4 shows the survival rate (\%) in F1 progeny originating from the lowDR experiment. Survival rates were higher than $80 \%$ and $60 \%$ at 2 and $10 \mathrm{~d}$, respectively, for all exposure conditions. No significant effect of treatments and control was observed in the progeny coming from $10 \mathrm{~d}$-irradiated adults. Similar results were observed for the progeny 
coming from 24 d-irradiated adults. A significant difference was observed between 5 and 289 F1R5 (Kruskal-Wallis test: $\mathrm{p}=0.049, \mathrm{n}=6$ ) at 22 days of exposure. No significant differences were observed for the hatching rate (\%) at $48 \mathrm{~h}$ (data not shown).

For the irradiated and non-irradiated (F1 Recovery) larvae (Figure 5), 100\% died after $120 \mathrm{~h}$ of highDR exposure, although the average survival rate for the control condition was 84 $293 \pm 11 \%$. In the control condition, the mortality rate was low and remained constant from 24 294 hpf. F1 irradiated (51\%) and F1 Recovery (58\%) survival rate at 24 hpf was low compared to 295 the control and ranged between 16 to $96 \%$, indicating a high spawn variability (SD Figure 2). 296 Drastic effects seemed to appear more rapidly for F1 irradiated larvae than for F1 Recovery 297 larvae (SD Figure 2).

Figure 6 shows the survival rate (\%) in F1 progeny coming from the highDR experiment where adults were placed in non-irradiated exposure conditions (F0 Recovery) 300 over 63 days. Fish were induced to spawn after 6, 36 and 63 days. Drastic effects of adult 301 irradiation on survival progeny rate lasted for at least 6 days ( $35 \pm 22, n=11$ spawns) and until 302 36 days ( $48 \pm 37, \mathrm{n}=8$ spawns). All larvae alive at $48 \mathrm{~h}$ from F0R0d, F0 R6d and F0 R36d, died at $96 \mathrm{~h}$. After 63 days in non-irradiated conditions, the progeny survival rate remained 304 high $(>85 \%, \mathrm{n}=11$ spawns $)$ and no significant difference was observed compared to the 305 control until $96 \mathrm{~h}$.

306 For the highDR experiment, the body sizes of F1 irradiated and F1 Recovery larvae decreased 307 significantly compared to the control (Figure 7). Similar results were also observed for non308 irradiated 72 h-larvae originating from F0 recovery conditions after 6 days. After $36 \mathrm{~d}$ in non309 irradiated conditions (F0 R36d), the body sizes of non-irradiated progeny showed no 310 significant difference compared to the controls although $100 \%$ of mortality at $120 \mathrm{~h}$ was 
311 observed. The surface of vitellus and pericardia area also showed no statistical difference with

312 the controls (data not shown).

Oxidative stress

Figure 8 shows ROS production in F1-progeny coming from the lowDR experiment.

315 Irradiation at $5 \mathrm{mGy} \mathrm{h}^{-1}$ led to an increase of ROS production in $4 \mathrm{~d}$-exposed larvae coming

316 from $24 \mathrm{~d}$-adult exposure. However, F1 R progeny exposed over $4 \mathrm{~d}$ at both dose rates

317 showed a significant increase in ROS production for larvae coming from $10 \mathrm{~d}$ - and $24 \mathrm{~d}$-adult

318 exposure. No effects were observed in larvae (irradiated and recovery) exposed over $10 \mathrm{~d}$

319 (Figure 10B).

Genotoxic effects

Figure 9 shows DNA damage measured in progeny coming from $24 \mathrm{~d}$-adults in the lowDR experiment, expressed by the tail moment. The progeny were placed in irradiated and non-irradiated conditions (F1 Recovery) over 10 days. Significant DNA damage was noticed at $4 \mathrm{~d}$ for irradiated $\left(0.5 \mathrm{mGy} \mathrm{h}^{-1}: 11.3 \pm 4.3 \% ; 5 \mathrm{mGy} \mathrm{h}^{-1}: 14.4 \pm 2.1 \%\right)$ and non-irradiated larvae (F1R: $0.5 \mathrm{mGy} \mathrm{h}^{-1}: 8.4 \pm 3 \%$ ) compared to the controls (x10). At $10 \mathrm{~d}$, the tail moment showed no difference between the conditions.

Figure 10A shows DNA damage expressed by the tail moment in the progeny coming from $10 \mathrm{~d}$-adult fish from the highDR experiment. The progeny was collected in irradiated and non-irradiated conditions (F1 Recovery) for $24 \mathrm{~h}$. The high mortality rate did not allow

330 larval collection at 4 and $10 \mathrm{~d}$. A significant increase of the tail moment was observed

331 between the control, irradiated (x6.5) and non-irradiated (x5) conditions. 10B-C shows DNA damage in the gonads of males and females after 10 days of irradiation. DNA damage 
333 increased for both sexes compared to the control. The effects were more pronounced for 334 males (x3) than for females (x1.7).

\section{DISCUSSION}

In the present work, embryo-larval and adult fish stages were exposed to $0.5,5$ and 50

$337 \mathrm{mGy} \mathrm{h}{ }^{-1}\left({ }^{137} \mathrm{Cs}\right.$ gamma radiation) to augment the dataset of gamma ray effects after parental 338 and progeny exposure.

Zebrafish as a relevant model for multigenerational studies

Reproduction was achieved for almost all couples and with a high egg survival rate (93

$341 \pm 7 \%$ at $3 \mathrm{hpf}$ for both control conditions, $\mathrm{n}=19$ ), confirming the relevance of this model for

342 multigenerational studies (Lawrence et al. 2012; Simon et al. 2014). Differences in

343 reproductive performances were observed between the controls used in both lowDR and

344 highDR experiments. The body weights of the control adults in both experiments was

345 significantly different and could explain the differences in fecundity. Indeed, zebrafish

346 fecundity, and more generally reproduction performance, can be influenced by the quality of

347 the diet, the female body size and environmental enrichment (Karga et al. 2017; Lawrence

348 2007; Lawrence et al. 2012; Wafer et al. 2016). It is important to note that although zebrafish

349 reproduce easily in laboratory conditions, assessing inter-individual variability of

350 reproductive performances requires a large number of couples.

351 No effect of irradiation was observed on adult reproduction performance

352 For the testes dose rates, irradiation did not alter the reproductive capacity. Many

353 pollutants which contribute to oxidative stress are known to alter reproductive performance,

354 indicating that this physiological function may be sensitive to changes in the environment 
355 (Faßbender et al. 2013; Newman et al. 2015; Simon et al. 2014; Wang et al. 2011).

356 Perturbation of reproduction was previously observed in other fish species. Woodhead (1977)

357 demonstrated that the total fecundity of guppies (Poecilia reticulata) was markedly reduced at

358 dose rates of $1.7,4$ and $12.7 \mathrm{mGy} \mathrm{h}^{-1}$ without drastic impacts on the mortality rate and

359 survival of offspring. Rackham et al. (1984) demonstrated that spermatogenesis of adult

360 butterfly splitfins (Ameca splendens) was disrupted (no production of sperm) after $7.3 \mathrm{mGy} \mathrm{h}^{-}$

$361{ }^{1}$ of exposure over 52 days and that developing oocytes were less sensitive to the effects of

362 radiation than spermatogenesis. Knowles (2002) observed a significant decrease in adult

363 zebrafish in the mean number of eggs per spawn after 30 days at $7.4 \mathrm{mGy} \mathrm{h}^{-1}$. Compared to

364 this study, the toxic modes of action seem to be strongly influenced by the biological model

365 and the experimental conditions of the dose rates. Under our experimental conditions, adult

366 zebrafish stage did not exhibit sensitivity.

367 Drastic effects from irradiation on progeny survival were observed and transferred from 368 adult fish

Drastic effects on progeny were only observed after high dose rate exposure and certainly had a detrimental effect at the population level. After exposure of adults to $5 \mathrm{mGy} \mathrm{h}^{-}$

$371{ }^{1}$ over 10 or 24 days (cumulative dose rates of 1.2 and $2.8 \mathrm{~Gy}$, respectively), no effect on 372 progeny survival rate was observed until after 22 days. The range of these induced effects (5-

$37350 \mathrm{mgGy} \mathrm{h}^{-1}$ ) is narrow and encourages us to more precisely determine the $\mathrm{EDR}_{10}$. The non-

374 irradiated progeny of 27 d-F0 exposed to $53 \mathrm{mGy} \mathrm{h}^{-1}$ (34.3 Gy) previously showed a 100\%

375 mortality rate occurring at the gastrulation stage ( $8 \mathrm{hpf}$ ) (Hurem et al. 2017a). In this study,

376 drastic effects appeared at a lower cumulative dose (12 Gy) for the same dose rate. These

377 results raise questions regarding the best criteria (cumulative dose versus dose rate) for

378 measuring gamma radiation exposure in the ERA. 
The experimental design for the lowDR and highDR experiments did not allow the identical cumulative dose to be obtained. It could potentially be beneficial to vary the duration of exposure ( $1 \mathrm{~d}$ at $50 \mathrm{mGy} \mathrm{h}^{-1} ; 100 \mathrm{~d}$ to $0.5 \mathrm{mGy} \mathrm{h}^{-1}$ ) to compare the effects obtained at the same cumulative dose.

Adverse effects seemed to be due to adult exposure since (i) irradiated and recovery progeny showed identical effects compared to the control, and (ii) direct irradiation of embryos at this high dose rate did not cause significant mortality as confirmed in this study and by Simon et al, 2011. Vertebrate embryos are particularly sensitive to ionizing radiation, due to a high rate of cell division and migration (Hu et al. 2016; Hurem et al. 2017a; Jarvis et al. 2003; Rhee et al. 2012). The sensitivity of early stages (development and antioxidant enzymes activities) has already been demonstrated; 6hpf-embryos were more sensitive than 12- and 24-hpf embryos to gamma irradiation (0.01-1 Gy) (Hu et al. 2016). However, we demonstrated here that the sensitivity of the progeny to ionizing radiation was particularly high when they originated from irradiated parents.

Parental effects observed in the highDR experiment were reversible, as they disappeared when adults were placed in non-irradiated conditions for between 36 and 63 days. These results suggest F0 recovery of reproductive capacity. The F0 adults zebrafish exposed to $53 \mathrm{mGy} \mathrm{h}^{-1}$ during 27 days ( $31 \mathrm{~Gy}$ ) and placed in non-irradiated conditions failed to

397 produce viable offspring 1.5 year after irradiation (Hurem et al. 2017a). The differences in terms of experimental design and cumulative dose between the present study and that of Hurem et al. (2017) encouraged us to elucidate the mechanisms behind the transfer from adult

400 to progeny and the F0 recovery induction over time. 
402 generated during oogenesis and supplied to the egg. Yolk lipoprotein nutrients, vitamins, 403 hormones, mRNA transcripts, and DNA methylation statuses have been identified as markers 404 of egg quality. The damage to these maternal products could also explain the drastic effects 405 observed in the progeny. Note that the period of maternal control of embryonic development 406 varies among animals and could explain difference of ionizing radiation effects between 407 species (Abrams et al. 2009; Vastenhouw et al. 2019). Among transferred maternal products, 408 cortisol is essential for early development (Faught et al. 2016; Nesan et al. 2013; Nesan et al. 409 2016). Then, de novo synthesis of cortisol starts after hatching (48 hpf) (Nesan et Vijayan 2016). Finally, elevated cortisol levels in embryos leads to the same effects (mortality, 411 pericardial oedema and heart malformation) (Nesan et al. 2012) observed in this study.

412 Moreover, high levels of cortisol in females may directly impact estradiol production, 413 possibly affecting vitellogenin production and its incorporation into the oocyte, leading to 414 drastic effects in the progeny. In this study, we hypothesize that the high dose rates of gamma 415 irradiation could have led to an alteration of the cortisol deposition and its transfer to eggs, 416 which may have resulted in altered offspring phenotypes.

\section{ROS production and genotoxicity after irradiated and recovery conditions}

From potentially toxic mechanisms, the genotoxicity and ROS induction were assessed.

419 Gamma irradiation is known to induce ROS formation in zebrafish larvae (Gagnaire et al. 2015; Jarvis et Knowles 2003). In this study, ROS production compared to the control was increased after $4 \mathrm{~d}$ of exposure of larvae originating from adults exposed during 10 and 24 days. Recovery larvae showed ROS production, without being irradiated. ROS production was higher in F1 recovery larvae than in irradiated larvae (originating from F0-10d). Once again, adult exposure led to high ROS production in larvae. This would seem to be a 
consequence of an effect inherited from the parents. Results were similar to those observed in other exposure conditions (dose rate, recovery duration) by Hurem et al, 2017.

As no effect was observed in $10 \mathrm{~d}$-larvae, the oxidative stress induced by gamma irradiation seems to be transitory. The activities of antioxidant enzymes are known to change in a developmental stage-dependent manner. However, larval ROS production in $4 \mathrm{~d}$ larvae was increased by gamma irradiation and persisted in F1 recovery condition. We hypothesized that under our experimental conditions, irradiation of the progeny led to an induction of protective agents that could counteract ROS production and re-establish a healthy cellular redox balance. Antioxidant enzyme activities could be assessed in further experiments in 10 d-irradiated larvae to test this hypothesis.

Significant genotoxic effects were observed at $4 \mathrm{~d}$-irradiated and non-irradiated progeny coming from adults exposed in the lowDR experiment $\left(0.5\right.$ and $\left.5 \mathrm{mGy} \mathrm{h}^{-1}\right)$ during 24 days. High inter-individual variability was however observed for the lowDR experiment, preventing the highlighting of significant differences.

Genotoxicity has previously been demonstrated in eggs exposed to gamma rays in chronic or acute experiments (Gagnaire et al. 2015; Praveen Kumar et al. 2017; Simon et al. 2011b) or to non-radioactive pollutants (Kosmehl et al. 2008; Vicquelin et al. 2011). In this study, tail moment values were comparable to those measured in eggs/larvae exposed over $4 \mathrm{~d}$ at $24 \mathrm{mGy} \mathrm{h}^{-1}$ (Gagnaire et al. 2015). Thus, these results suggest an increase in the intensity of genotoxic effects due to parental irradiation and confirm the molecular effects inherited from the parents. The genotoxic effects decreased at $10 \mathrm{~d}$, suggesting a better efficiency of DNA repair mechanisms at this larval stage, potentially related to a better efficiency of the 
447 antioxidant system. It would be interesting to measure some of the DNA repair mechanisms 448 (as gamma H2AX activity) in order to confirm this hypothesis.

Irradiation of adults at high dose rates led to significant genotoxic effects on irradiated

450 and non-irradiated progeny as early as $1 \mathrm{~d}$, unlike results obtained at lower dose rates.

451 However, the levels of genotoxic effects at $1 \mathrm{~d}$ remained lower than the ones measured at $4 \mathrm{~d}$ 452 in the lowDR experiment which did not lead to a high mortality rate. The comparison between 453 the different stages of development remains difficult and we have to take into account 454 possible differences in reparation mechanism induction between the different stages to explain 455 the relationship between mortality and genotoxicity effects. We suggest that the early live 456 stage could be more sensitive than the later life stage. High irradiation exposure led to significant genotoxic effects on adult gonads. However, 458 the effects were lower than those measured after low uranium waterborne exposure (Simon et 459 al. 2018). Significant differences were also observed in the controls between males and 460 females, as previously observed in other studies (Simon et al. 2018). Moreover, irradiation 461 effects seemed more pronounced for males than for females. Further studies may be 462 completed by the determination of genotoxicity levels in zebrafish sperm, allowing a better 463 link with genotoxicity observed in the progeny, as proposed by Reinardy et al. (2013). Indeed, 464 during spermatogenesis, chromatin is processed and packaged and contact between DNA 465 and nuclear matrix is reorganized. Furthermore, the epigenetic pattern is also totally re466 modelled and transcription is stopped. All these events contribute to the control of embryo 467 development in the early-life stages (Herráez et al. 2017). 


\section{CONCLUSION}

These results on fish reproductive performance after gamma irradiation provide additional information for ERAs. Drastic effects on progeny and consequently on population levels were observed at dose rates between 5 and $50 \mathrm{mGy} \mathrm{h}^{-1}$, confirming the DCRL values. However, it is important to note a difference in the sensitivity between the trout reference organism and the Danio rerio, the model organism in our study. Moreover, this study highlights that parental exposure leads to significant effects in the progeny at the molecular level (ROS, genotoxicity), even at low dose rates $\left(0.5 \mathrm{~m} \mathrm{~Gy} \mathrm{~h}^{-1}\right)$. The consequences of these molecular effects will need to be studied following chronic exposure. The results encourage us to take into account the consequences of transmitted generational (i.e. heritable) effects for the determination of DCRL values. This study improves our understanding of the consequences of multigenerational exposure conditions for a better radioprotection of aquatic ecosystems. It confirms the difference in sensitivity of model species and identifies a narrow range of occurrence of drastic effects. It also acts as an incentive to acquire new data from multigenerational chronic exposure at low dose levels.

\section{REFERENCES}

Abrams EW, Mullins MC. 2009. Early zebrafish development: It's in the maternal genes. Curr Opin Gen Dev 19:396-403.

\section{Adam-Guillermin C, Pereira S, Della-Vedova C, Hinton T, Garnier-Laplace J. 2012.}

Genotoxic and reprotoxic effects of tritium and external gamma irradiation on aquatic animals. Rev Environ Contam Toxicol 220:67-103. 
490 Bonzom JM, Hättenschwiler S, Lecomte-Pradines C, Chauvet E, Gaschak S, Beaugelin-

491 Seiller K, Della-Vedova C, Dubourg N, Maksimenko A, Garnier-Laplace J, Adam-Guillermin

492 C. 2016. Effects of radionuclide contamination on leaf litter decomposition in the Chernobyl

493 exclusion zone. Sci Total Environ 562:596-603.

494 Brown JE, Alfonso B, Avila R, Beresford NA, Copplestone D, Pröhl Gulanovsky A. 2008.

495 The ERICA Tool. J Environ Radioact 99: 1371-1383.

496 Buisset-Goussen A, Goussen B, Della-Vedova C, Galas S, Adam-Guillermin C, Lecomte497 Pradines C. 2014. Effects of chronic gamma irradiation: A multigenerational study using 498 Caenorhabditis elegans. J Environ Radioact 137:190-197.

499 Choi VWY, Cheng SH, Yu KN. 2010. Radioadaptive response induced by alpha-particle500 induced stress communicated in vivo between zebrafish embryos. Environ Sci Tech 44: 88295018834.

502 Choi VWY, Yu KN. 2015. Embryos of the zebrafish Danio rerio in studies of non-targeted 503 effects of ionizing radiation. Cancer Lett 356:91-104.

504 Faßbender C, Braunbeck T. 2013. Reproductive and genotoxic effects in zebrafish after 505 chronic exposure to methyl methanesulfonate in a multigeneration study. Ecotoxicology $506 \quad 22: 825-837$.

507 Faught E, Best C, Vijayan MM. 2016. Maternal stress-associated cortisol stimulation may 508 protect embryos from cortisol excess in zebrafish. R Soc Open Sci 3(2): 160032. 
Fuller N, Ford AT, Nagorskaya LL, Gudkov DI, Smith JT. 2018. Reproduction in the

510 freshwater crustacean Asellus aquaticus along a gradient of radionuclide contamination at

511 Chernobyl. Sci Total Environ 628-629:11-17.

512 Gagnaire B, Cavalié I, Pereira S, Floriani M, Dubourg N, Camilleri V, Adam-Guillermin C.

513 2015. External gamma irradiation-induced effects in early-life stages of zebrafish, Danio

514 rerio. Aquat Toxicol 169:69-78.

515 Garnier-Laplace J, Della-Vedova C, Andersson P, Copplestone D, Cailes C, Beresford NA,

516 Howard BJ, Howe P, Whitehouse P. 2010. A multi-criteria weight of evidence approach for

517 deriving ecological benchmarks for radioactive substances. J Radiol Prot 30:215-233.

518 Garnier-Laplace J, Della-Vedova C, Gilbin R, Copplestone D, Hingston J, Ciffroy P. 2006.

519 First derivation of predicted-no-effect values for freshwater and terrestrial ecosystems

520 exposed to radioactive substances. Environ SciTechn 40:6498-6505.

521 Herráez MP, Ausió J, Devaux A, González-Rojo S, Fernández-Díez C, Bony S, Saperas N,

522 Robles V. 2017. Paternal contribution to development: Sperm genetic damage and repair in

523 fish. Aquaculture 472:45-59.

524 Hu M, Hu N, Ding D, Zhao W, Feng Y, Zhang H, Li G, Wang Y. 2016. Developmental

525 toxicity and oxidative stress induced by gamma irradiation in zebrafish embryos. Radiat 526 Environ Biophys 55:441-450.

527 Hurem S, Gomes T, Brede DA, Lindbo Hansen E, Mutoloki S, Fernandez C, Mothersill C,

528 Salbu B, Kassaye YA, Olsen AK, Oughton D, Aleström P, Lyche JL. 2017a. Parental gamma

529 irradiation induces reprotoxic effects accompanied by genomic instability in zebrafish (Danio

530 rerio) embryos. Environ Res 159:564-578. 
531 Hurem S, Martín LM, Brede DA, Skjerve E, Nourizadeh-Lillabadi R, Lind OC, Christensen

532 T, Berg V, Teien HC, Salbu B, Oughton DH, Aleström P, Lyche JL. 2017b. Dose-dependent

533 effects of gamma radiation on the early zebrafish development and gene expression. PLoS

534 ONE 12(6): $\mathrm{e} 0179259$

535 Hurem S, Martín LM, Lindeman L, Brede DA, Salbu B, Lyche JL, Aleström P, Kamstra JH.

536 2018. Parental exposure to gamma radiation causes progressively altered transcriptomes

537 linked to adverse effects in zebrafish offspring. Environ Pollut 234:855-863.

538 ICRP. 2012. Protection of the environment under different exposure situtations, Annals of the 539 ICRP.

540 Jaafar L, Podolsky RH, Dynan WS. 2013. Long-Term Effects of Ionizing Radiation on Gene

541 Expression in a Zebrafish Model. PLoS ONE 8(7):e69445.

542 Jarvis RB, Knowles JF. 2003. DNA damage in zebrafish larvae induced by exposure to low-

543 dose rate $\gamma$-radiation: detection by the alkaline comet assay. Mutat Res: 41, 63-69.

544 Kamstra JH, Hurem S, Martin LM, Lindeman LC, Legler J, Oughton D, Salbu B, Brede DA,

545 Lyche JL, Aleström P. 2018. Ionizing radiation induces transgenerational effects of DNA

546 methylation in zebrafish. Sci Rep 8(1):15373.

547 Karga J, Mandal SC. 2017. Effect of different feeds on the growth, survival and reproductive

548 performance of zebrafish, Danio rerio (Hamilton, 1822). Aquac Nutr 23:406-413.

549 Knowles JF. 2002. An investigation into the effets of chronic radiation on fish. Report

$550 \quad$ Environment Agency, Bristol, UK. 
Kosmehl T, Hallare AV, Braunbeck T, Hollert H. 2008. DNA damage induced by

552 genotoxicants in zebrafish (Danio rerio) embryos after contact exposure to freeze-dried 553 sediment and sediment extracts from Laguna Lake (The Philippines) as measured by the 554 comet assay. Mut Res 650: 1-14.

Lawrence C. 2007. The husbandry of zebrafish (Danio rerio): A review. Aquaculture 269, 155620.

Lawrence C, Best J, James A, Maloney K. 2012. The effects of feeding frequency on growth 558 and reproduction in zebrafish (Danio rerio). Aquaculture 368:103-108.

559 Lecomte-Pradines C, Bonzom JM, Della-Vedova C, Beaugelin-Seiller K, Villenave C, 560 Gaschak S, Coppin F, Dubourg N, Maksimenko A, Adam-Guillermin C, Garnier-Laplace J. 561 2014. Soil nematode assemblages as bioindicators of radiation impact in the Chernobyl 562 Exclusion Zone. Sci Total Environ 490: 161-170.

563 Lemos J, Neuparth T, Trigo M, Costa P, Vieira D, Cunha L, Ponte F, Costa PS, Metello LF, 564 Carvalho AP. 2017. Single Low-Dose Ionizing Radiation Induces Genotoxicity in Adult 565 Zebrafish and its Non-Irradiated Progeny. Bull Environ Contam Toxicol 98: 190-195.

566 Lerebours A, Gudkov D, Nagorskaya L, Kaglyan A, Rizewski V, Leshchenko A, Bailey EH, 567 Bakir A, Ovsyanikova S, Laptev G, Smith JT. 2018. Impact of Environmental Radiation on 568 the Health and Reproductive Status of Fish from Chernobyl. Environ Sci Techn 52:94425699450.

570 McAleer MF, Davidson C, Davidson WR, Yentzer B, Farber SA, Rodeck U, Dicker AP. 5712005 . Novel use of zebrafish as a vertebrate model to screen radiation protectors and 572 sensitizers. Int J Radiat Oncol Biol Phys 61:10-13. 
573 Nesan D, Vijayan MM. 2012. Embryo exposure to elevated cortisol level leads to cardiac

574 performance dysfunction in zebrafish. Mol Cell Endocrinol 363: 85-91.

575 Nesan D, Vijayan MM. 2013. Role of glucocorticoid in developmental programming:

576 Evidence from zebrafish. Gen Comp Endocrinol 181:35-44.

577 Nesan D, Vijayan MM. 2016. Maternal Cortisol Mediates Hypothalamus-Pituitary-Interrenal

578 Axis Development in Zebrafish. Scientific Reports 6:22582

579 Newman TAC, Carleton CR, Leeke B, Hampton MB, Horsfield JA. 2015. Embryonic

580 oxidative stress results in reproductive impairment for adult zebrafish. Redox Biology 6:648-

581655.

582 Ng CYP, Cheng SH, Yu KN. 2017. Photon hormesis deactivates alpha-particle induced

583 bystander effects between zebrafish embryos. Radiat Phys Chem 133:72-80.

584 Parisot F, Bourdineaud JP, Plaire D, Adam-Guillermin C, Alonzo F. 2015. DNA alterations

585 and effects on growth and reproduction in Daphnia magna during chronic exposure to gamma

586 radiation over three successive generations. Aquat Toxicol 163:27-36.

587 Praveen Kumar MK, Shyama SK, Kashif S, Dubey SK, Avelyno D, Sonaye BH, Kadam

588 Samit B, Chaubey RC. 2017. Effects of gamma radiation on the early developmental stages of

589 Zebrafish (Danio rerio). Ecotoxicol Environ Saf 142:95-101.

590 Rackham BD, Woodhead DS. 1984. Effects of Chronic $\gamma$-irradiation on the gonads of adult

591 Ameca Splendens (Osteichthyes: Teleostei). Int J Radiat Biol Relat Stud Phys Chem Med $592 \quad 45: 645-656$. 
593 Reinardy HC, Syrett JR, Jeffree RA, Henry TB, Jha AN. 2013. Cobalt-induced genotoxicity

594 in male zebrafish (Danio rerio), with implications for reproduction and expression of DNA 595 repair genes. Aquat Toxicol 126:224-230.

596 Rhee JS, Kim BM, Kang CM, Lee YM, Lee JS. 2012. Gamma irradiation-induced oxidative 597 stress and developmental impairment in the hermaphroditic fish, Kryptolebias marmoratus 598 embryo. Environ Toxicol Chem 31:1745-1753.

599 Simon O, Floc'h E, Geffroy B, Frelon S, 2014. Exploring ecotoxicological fish bioassay for 600 the evaluation of uranium reprotoxicity. Environ Toxicol Chem 33:1817-1824.

601 Simon O, Floriani M, Cavalie I, Camilleri V, Adam C, Gilbin R, Garnier-Laplace J. 2011a. 602 Internal distribution of uranium and associated genotoxic damages in the chronically exposed 603 bivalve Corbicula fluminea. J Environ Radioact 102:766-773.

604 Simon O, Gagnaire B, Camilleri V, Cavalié I, Floriani M, Adam-Guillermin C. 2018.

605 Toxicokinetic and toxicodynamic of depleted uranium in the zebrafish, Danio rerio. Aquat 606 Toxicol $197: 9-18$.

607 Simon O, Massarin S, Coppin F, Hinton TG, Gilbin R. 2011b. Investigating the embryo/larval 608 toxic and genotoxic effects of $\gamma$ irradiation on zebrafish eggs. J Environ Radioact 102:10396091044.

610 Singh NP, McCoy MT, Tice RR, Schneider EL. 1988. A simple technique for quantitation of 611 low levels of DNA damage in individual cells. Exp Cell Res 175:184-191. 
612 Sinha P, Arunachalam KD, Annamalai SK. 2018. Radio-protective dosimetry of Pangasius

613 sutchi as a biomarker, against gamma radiation dosages perceived by genotoxic assays.

614 Ecotoxicol Environ Saf 164:629-640.

615 Vastenhouw NL, Cao WX, Lipshitz HD. 2019. The maternal-to-zygotic transition revisited.

616 Development 146: 161471.

617 Vicquelin L, Leray-Forget J, Peluhet L, LeMenach K, Deflandre B, Anschutz P, Etcheber H,

618 Morin B, Budzinski H, Cachot J. 2011. A new spiked sediment assay using embryos of the

619 Japanese medaka specifically designed for a reliable toxicity assessment of hydrophobic 620 chemicals. Aquat Toxicol 105:235-245.

621 Wafer LN, Jensen VB, Whitney JC, Gomez TH, Flores R, Goodwin BS. 2016. Effects of 622 environmental enrichment on the fertility and fecundity of zebrafish (Danio rerio). $J$ Am 623 Assoc Lab Anim Sci 55:291-294.

624 Wang J, Zhu X, Zhang X, Zhao Z, Liu H, George R, Wilson-Rawls J, Chang Y, Chen Y. 625 2011. Disruption of zebrafish (Danio rerio) reproduction upon chronic exposure to TiO2 626 nanoparticles. Chemosphere 83:361-467.

627 Woodhead DS, 1977. The effects of chronic irradiation on the breeding performance of the 628 guppy, Poecilia reticulata (osteichthyes Teleostei). Int J Radiat Biol 32:1-22. 
635 Figure 1. Exposure duration, conditions and endpoints for lowDR and highDR experiments. 636 For each exposure condition, a control condition was included. For the lowDR experiment $637\left(0.5,5 \mathrm{mGy} \mathrm{h}^{-1}\right)$, adults were exposed over 24 days. Reproduction was assessed after 10 and 63824 days of irradiation. The progeny were then placed in irradiated and non-irradiated (F1 639 Recovery) exposure conditions over 10 and 22 days. For the highDR experiment (50 $\mathrm{mGy} \mathrm{h}^{-}$ $64{ }^{1}$ ), adults were exposed over 10 days. The progeny were then placed in irradiated and non641 irradiated (F1 Recovery) exposure conditions over 120 hours. 10d-irradiated adults were 642 placed in non-irradiated exposure (F0 Recovery) over 63 days. Reproduction was assessed 643 after 6, 36 and 63 days in F0 recovery conditions. The progeny were placed in non-irradiated 644 exposure conditions over 96 hours for each time point (6, 36 and 63 days).

Figure 2. Fecundity (number of egg per female) of F0 adults measured after 10 days of 647 exposure for both lowDR and highDR experiments (Treatment versus Control, *, Kruskal648 Wallis $\mathrm{p}=0.03$ ). $\mathrm{n}=$ number of spawns.

650 Figure 3. Individual (points) and average (histograms, means $\pm \mathrm{sd}$ ) survival rates (\%,) of F1 651 progeny at 24 and $48 \mathrm{~h}$. F1 progeny came from adults irradiated during 10 days for all 652 experiments. F1 R: F1 recovery condition, i.e progeny spawned by irradiated adults and 653 placed in non-irradiated conditions.

654 For lowDR experiment (control, 0.5, 5, R0.5, R5 $\mathrm{mGy} \mathrm{h}^{-1}$ ), survival rate was calculated from 6553 spawns (with 2 pseudo-replicates, 1 male+1 female). 
656 For highDR experiment (control, 50, R50 $\mathrm{mGy} \mathrm{h}^{-1}$ ), survival rate was calculated from 6

657 spawns ( 1 male+1 female). (Kruskal-Wallis test: Treatment versus Control, a: $p=0.024, b$ : $658 \mathrm{p}=0.015, \mathrm{c}: \mathrm{p}=0.006, \mathrm{~d}: \mathrm{p}=0.006 ; \mathrm{a}>\mathrm{b}>\mathrm{c}>\mathrm{d})$.

660 Figure 4. Survival rate (\%) of F 1 progeny over time for lowDR experiment. Data are means \pm 661 SD of two replicates of 80 eggs for 3 spawns per condition. (Kruskal-Wallis test: 5 versus 662 F1R, a: $p=0.049, n=6)$.

663 A. F1 progeny coming from adults irradiated during 10 days. Immediately after spawning, F1 664 progeny was placed in irradiated and in non-irradiated (F1R Recovery) exposure conditions 665 during 22 days.

666 B. F1 progeny coming from adults irradiated during 24 days. Immediately after spawning, F1 667 progeny was placed in irradiated exposure conditions during $10 \mathrm{~d}$.

669 Figure 5. Survival rate $(\%, n=6)$ of F1 progeny (3-4 hpf) over time. Progeny came from 10d670 irradiated adults for highDR experimentation. F1 Progeny were placed in irradiated and non671 irradiated (F1R, Recovery) exposure conditions over $120 \mathrm{~h}$. (Kruskal-Wallis test: Treatment 672 versus Control, $a: p=0.006, b: p=0.006, c: p=0.003, d: p=0.003$; $=0.003, f: p=0.003$ ).

674 Figure 6. Individual (points) and average (histograms, means \pm SD) survival rates $(\%, n=4-6)$ 675 of F 1 progeny after 24 and $48 \mathrm{~h}$. Progeny came from adults irradiated during 10 days and then 676 placed in non-irradiated conditions (F0R, Recovery) during $63 \mathrm{~d}$. (Kruskal Wallis test, 
677 Treatment versus Control, $a: p=0.015 n=12, b: p=0.0060 n=11, c: p=0.05 n=8, e: p=0.0058$

$678 \mathrm{n}=11, \mathrm{f}: \mathrm{p}=0.05 \mathrm{n}=11$ ).

679

680 Figure 7. Body length (mm) and typical aspect of $\mathrm{F} 1$ progeny at $72 \mathrm{~h}$. F1 progeny came from 681 adults exposed during $10 \mathrm{~d}$ (Irr. 10d) and $10 \mathrm{~d}$ followed by 6 days (F0 Irr. $10 \mathrm{~d}+\mathrm{F} 0 \mathrm{R}$ 6d) and 36 682 days in non-irradiated (F0 Irr. 10d+F0R 36d) conditions. (Kruskal Wallis test, Treatment 683 versus Control, *, $p<0.05$, F0Irr. 10d $p=0.002 n=20 ; 0.0049 n=20$, F0 Irr. 10d+F0R 6d, $684 p=0.00007 \mathrm{n}=33$, F0 irr. 10d+F0R 36d, $p=0.077, n=85)$.

685

686 Figure 8. ROS production measured in larval exposed during $4 \mathrm{~d}$ coming from F0 adults 687 exposed during $10(\mathrm{~A} 1)$ and $24 \mathrm{~d}(\mathrm{~A} 2)$ and in larval exposed during $10 \mathrm{~d}$ coming from $\mathrm{F} 0$ 688 adults exposed during $24 \mathrm{~d}(\mathrm{~B})$ of lowDR experiments. $\mathrm{Nd}$ : not determinate $\mathrm{n}=20$ per 689 condition, Anova test $*, p<0.05$.

690 Figure 9. DNA damage (Tail moment) in F1 progeny after 1, 4 and 10d of exposure. Progeny 691 came from adults irradiated during 24d for lowDR experiment. Progeny (3-4 hpf) were placed 692 in irradiated and non-irradiated (F1R, Recovery) conditions. Kruskal Wallis test, ${ }^{*}, \mathrm{p}<0.05$.

694 Figure 10. DNA damage (tail moment) in progeny (A: 1d, irradiated and non-irradiated 695 exposure (F1R, Recovery)) and in gonads of F0 adults (B: female, $\mathrm{C}$ : male) coming from highDR experiment. Kruskal Wallis test: * ${ }^{*}<0.05$. 


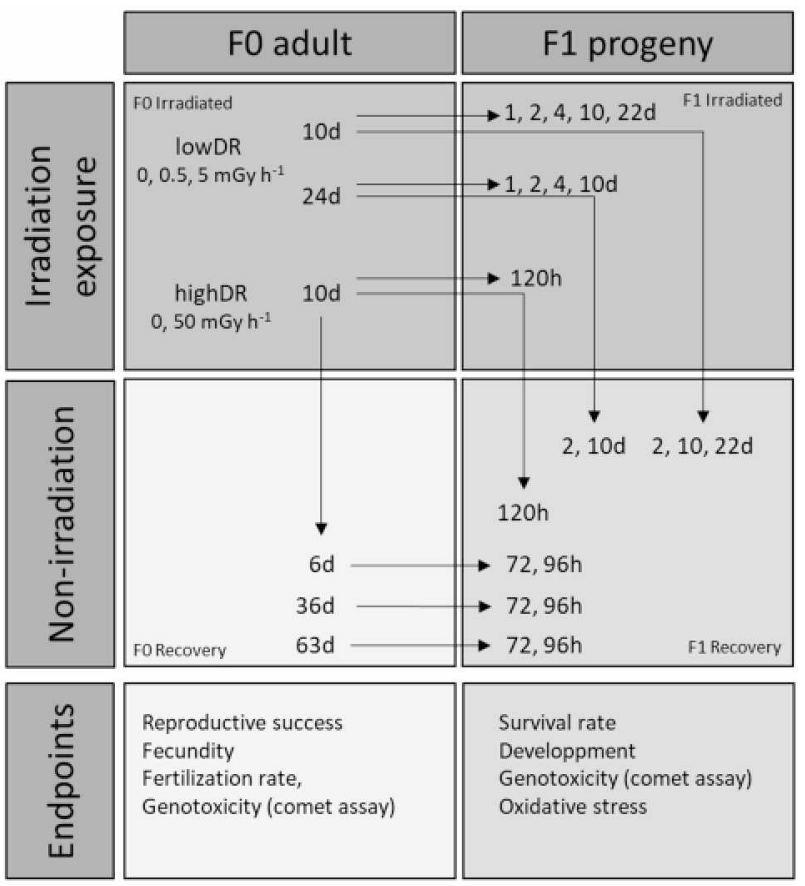

Figure 1. Exposure duration, conditions and endpoints for the lowDR and highDR experiments. For each exposure condition, a control condition was included. For the lowDR experiment $(0.5,5 \mathrm{mGy} h-1)$, adults were exposed over 24 days. Reproduction was assessed after 10 and 24 days of irradiation. The progeny were then placed in irradiated and nonirradiated (F1 Recovery) exposure conditions over 10 and 22 days. For the highDR experiment ( 50 mGy h-1), adults were exposed over 10 days. The progeny were then placed in irradiated and non-irradiated (F1 Recovery) exposure conditions over 120 hours. $10 \mathrm{~d}$-irradiated adults were placed in non-irradiated (FO Recovery) exposure conditions over 63 days. Reproduction was assessed after 6,36 and 63 days in Fo recovery conditions. The progeny were placed in non-irradiated exposure conditions over 96 hours for each time point ( 6,36 and 63 days). 


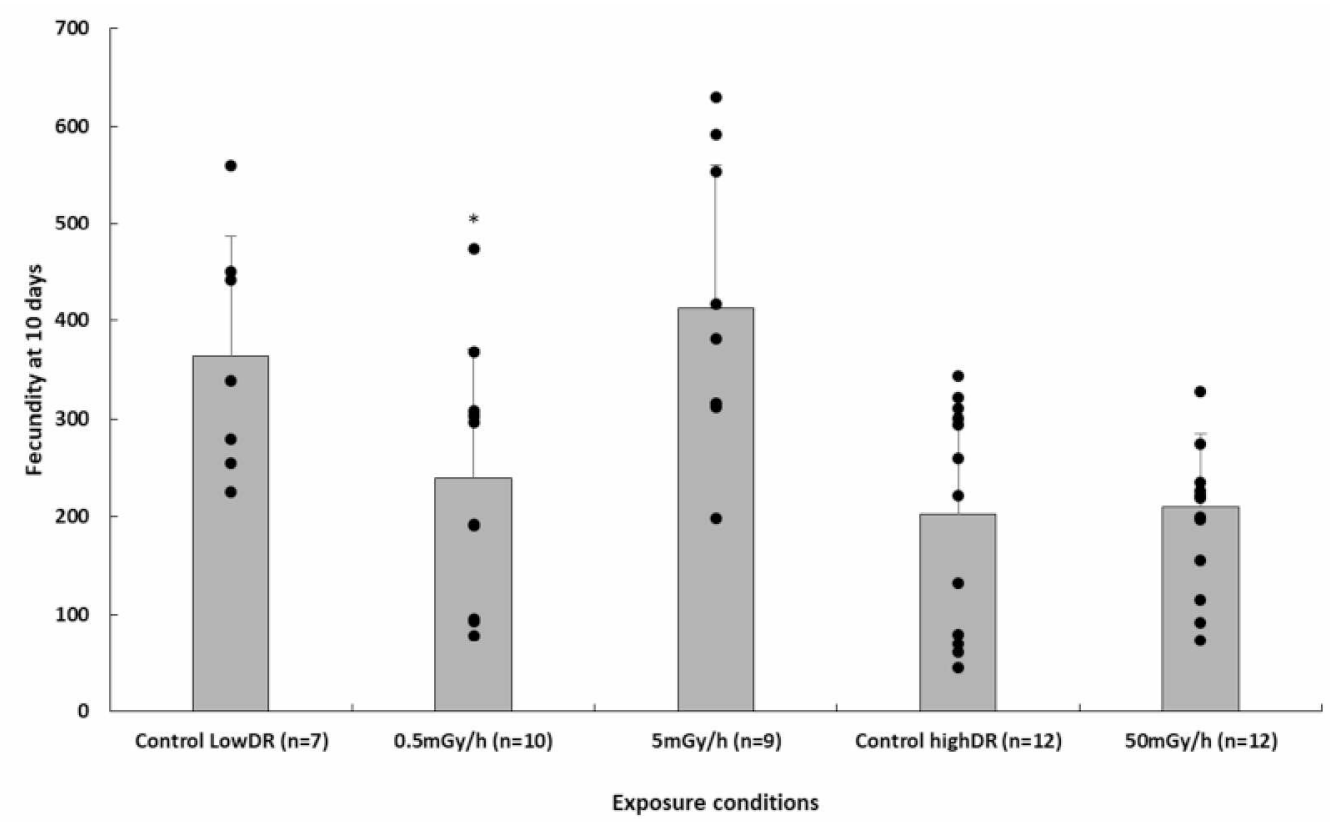

Figure 2. Fecundity (number of eggs per female) of FO adults measured after 10 days of exposure for both the lowDR and highDR experiments (Kruskal-Wallis test: Treatment versus Control, * $p=0.03$ ). n=number of spawns. 


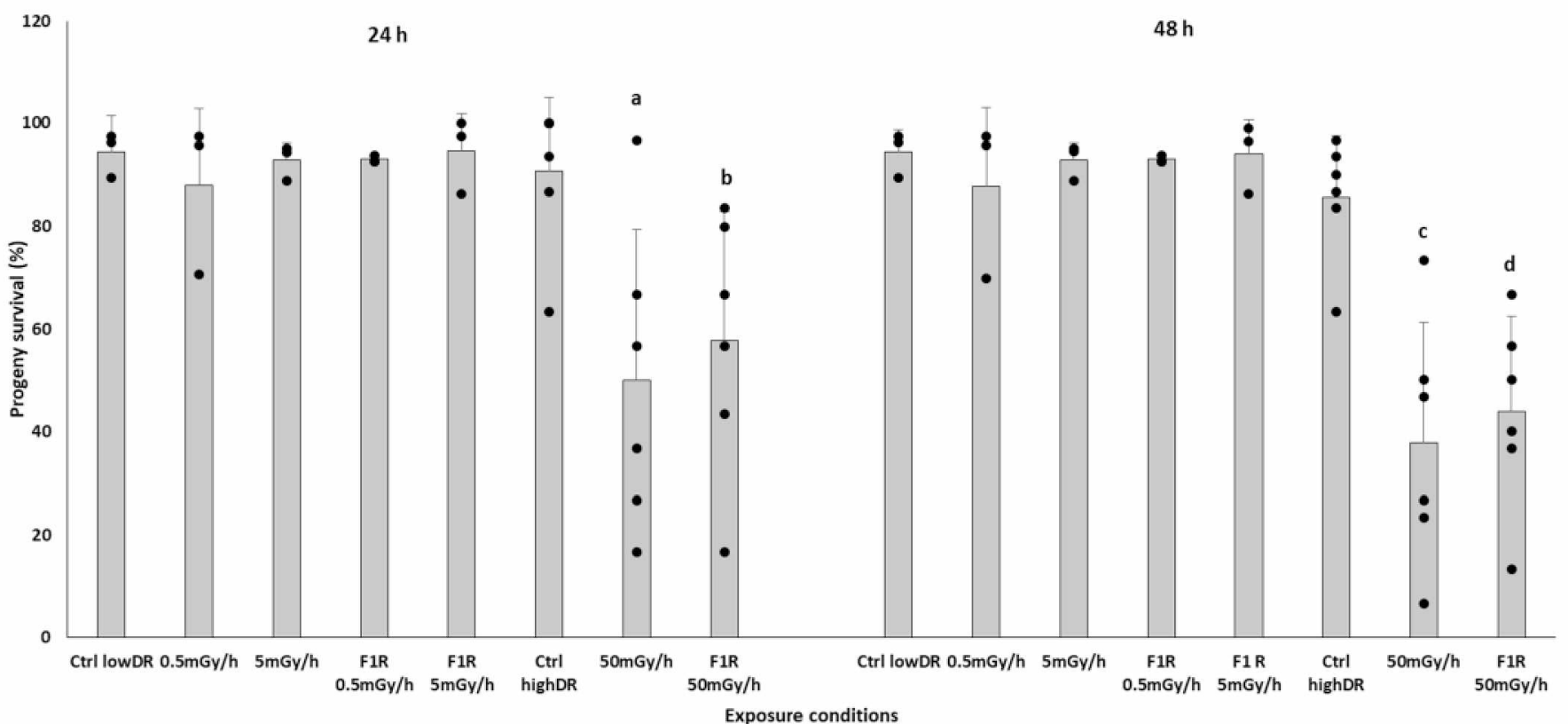

Figure 3. Individual (points) and average (histograms, means $\pm s d$ ) survival rates (\%, $n=x x$ ) of the F1 progeny at 24 and $48 \mathrm{~h}$. F1 progeny came from adults irradiated during 10 days for all experiments. F1 R: F1 recovery condition, i.e. progeny spawned by irradiated adults and placed in non-irradiated conditions.

For the lowDR experiment (control, $0.5,5, \mathrm{R0.5}, \mathrm{R} 5 \mathrm{mGy} \mathrm{h}^{-1}$ ), the survival rate was calculated from 3 spawns (with 2 pseudoreplicates, 1 male+1 female).

For the highDR experiment (control, 50, R50 $\mathrm{mGy} \mathrm{h}^{-1}$ ), the survival rate was calculated from 6 spawns ( 1 male+1 female). (Kruskal-Wallis test: Treatment versus Control, $a: p=0.024, b: p=0.015, c: p=0.006, d: p=0.006 ; a>b>c>d$ ). 

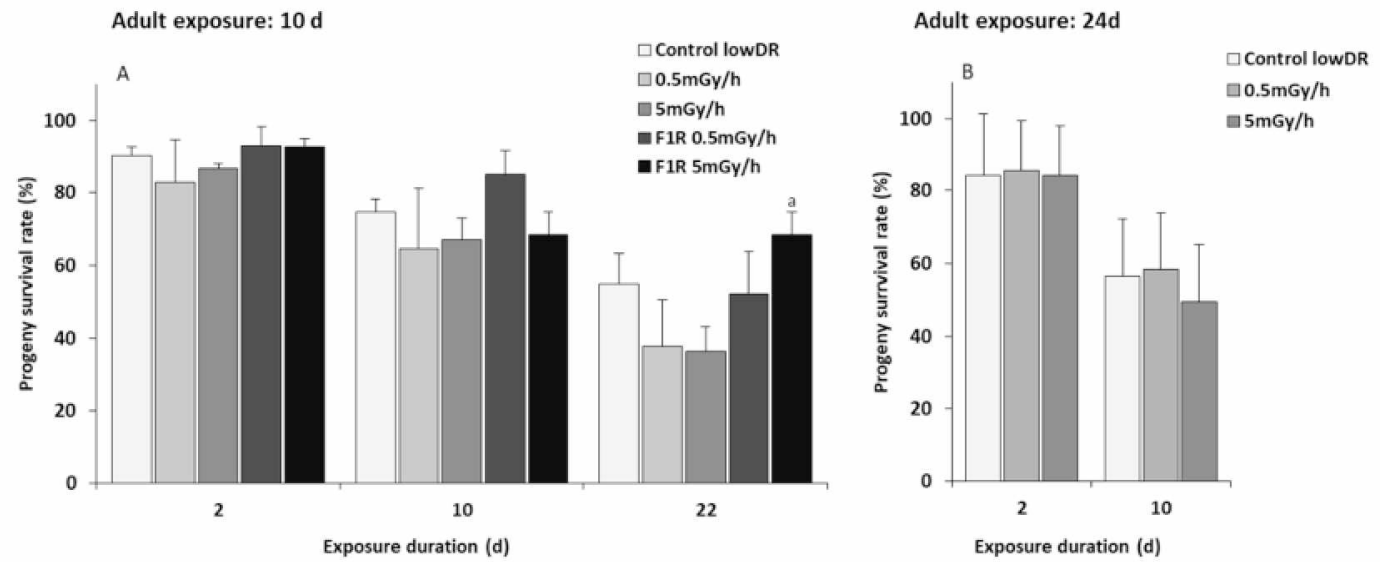

Figure 4. Survival rate (\%) of F1 progeny over time for the lowDR experiment. Data are means \pm SD of two replicates of 80 eggs for 3 spawns per condition. Kruskal-Wallis test: 5 versus F1R 5, a, $n=6, p=0.049$

A. F1 progeny coming from adults irradiated over 10 days. Immediately after spawning, the F1 progeny was placed in irradiated and in non-irradiated (F1R Recovery) exposure conditions over 22 days.

B. F1 progeny coming from adults irradiated over 24 days. Immediately after spawning, the F1 progeny was placed in irradiated exposure conditions over $10 \mathrm{~d}$. 


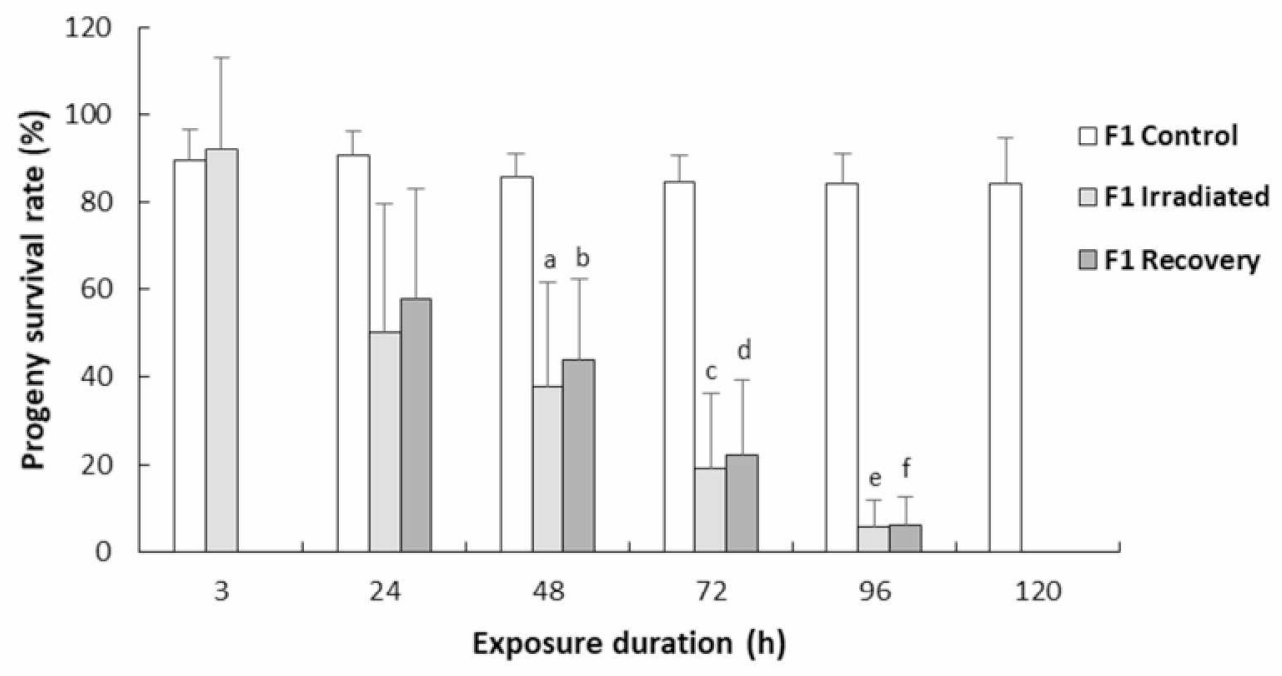

Figure 5. Survival rate (\%) of 6 F1 progeny ( $3-4 \mathrm{hpf}$ ) over $120 \mathrm{~h}$. The progeny came from $10 \mathrm{~d}$-irradiated adults from the highDR experiment. The F1 Progeny were placed in irradiated and non-irradiated (F1R, Recovery) exposure conditions over 120 h. (Kruskal-Wallis test: Treatment versus Control, $a: p=0.006, b: p=0.006, c: p=0.003, d: p=0.003 ; e:=0.003, f: p=0.003$ ). 


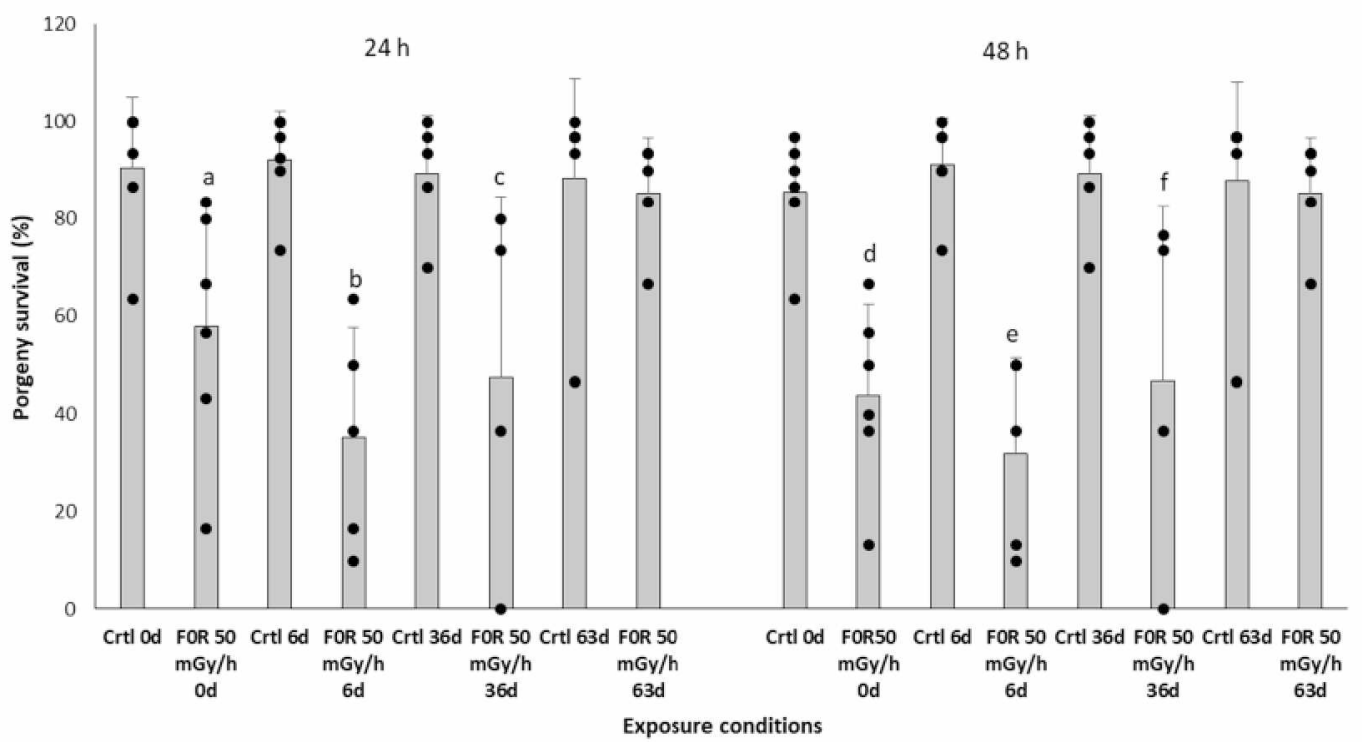

Figure 6. Individual (points) and average (histograms, means \pm SD) survival rates (\%, $n=4-6$ ) of F1 progeny after 24 and $48 \mathrm{~h}$. The progeny came from adults irradiated over 10 days and then placed in non-irradiated conditions (FOR, Recovery) over 63 d. Kruskal Wallis test: Treatment versus Control a: $p=0.015 n=12$, b: $p=0.0060 n=11, c: p=0.05 n=8$, e: $p=0.0058 n=11$, $p=0.05 n=11$. 


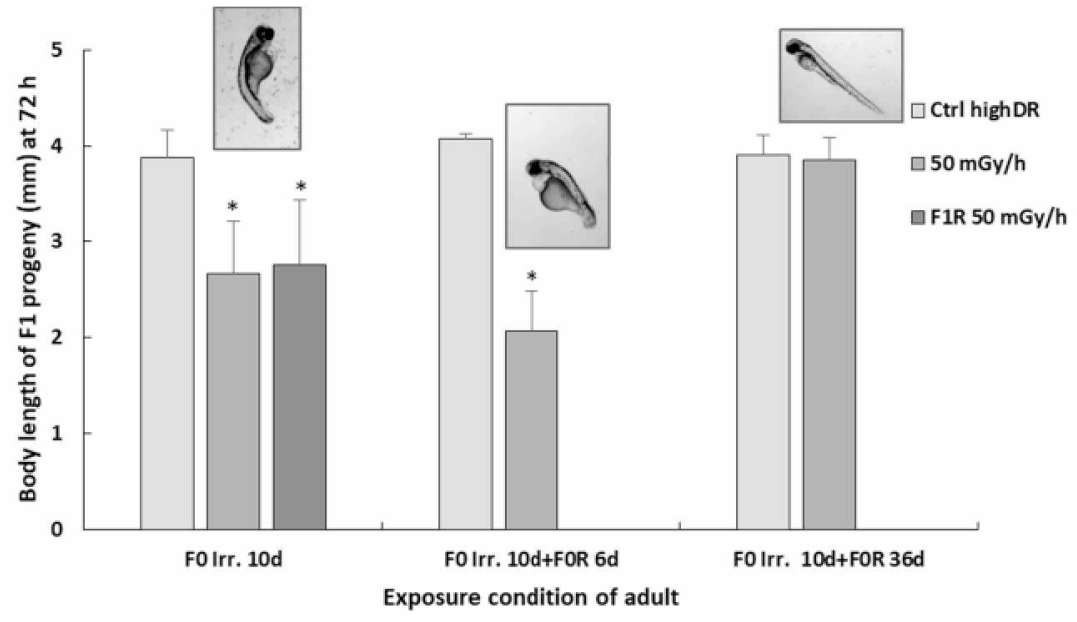

Figure 7. Body length $(\mathrm{mm})$ and typical aspect of F1 progeny at $72 \mathrm{~h}$. The F1 progeny came from adults exposed over $10 \mathrm{~d}$ (Irr. $10 \mathrm{~d}$ ) and $10 \mathrm{~d}$ followed by 6 days (FO Irr. 10d+FOR 6d) and 36 days in non-irradiated (FO Irr. 10d+FOR 36d) conditions. Kruskal Wallis test, Treatment versus Control *, $p<0.05$, FOIrr. 10d p=0.002 n=20; $0.0049 n=20$, FO Irr. 10d+FOR 6d, $p=0.00007 n=33$, FO irr. 10d+FOR 36d, $p=0.077, n=85$. 

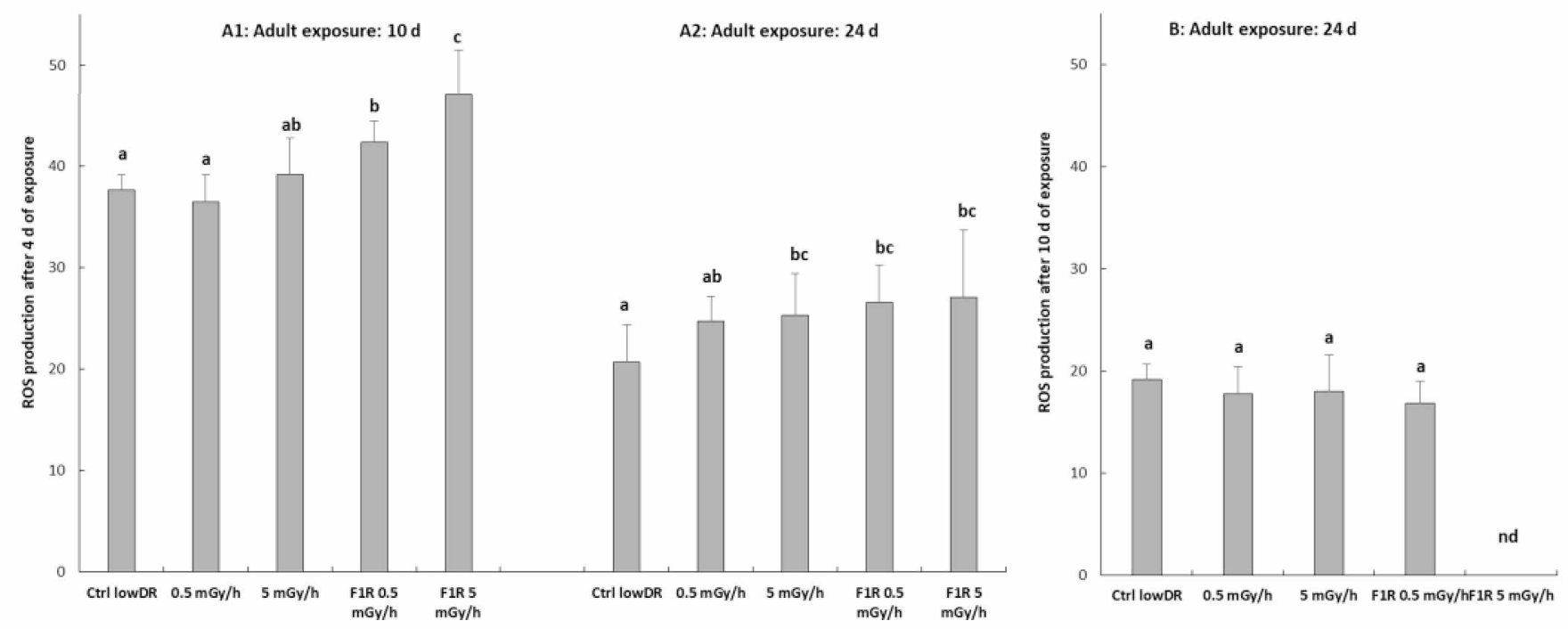

Figure 8. ROS production measured in larvae exposed over $4 \mathrm{~d}$ coming from F0 adults exposed over 10 (A1) and 24 $d$ (A2) and in larvae exposed during $10 \mathrm{~d}$ coming from F0 adults exposed over $24 \mathrm{~d}$ (B) of lowDR experiment. Nd: not determinate $\mathrm{n}=20$ per condition, Anova test *, $\mathrm{p}<0.05$. 


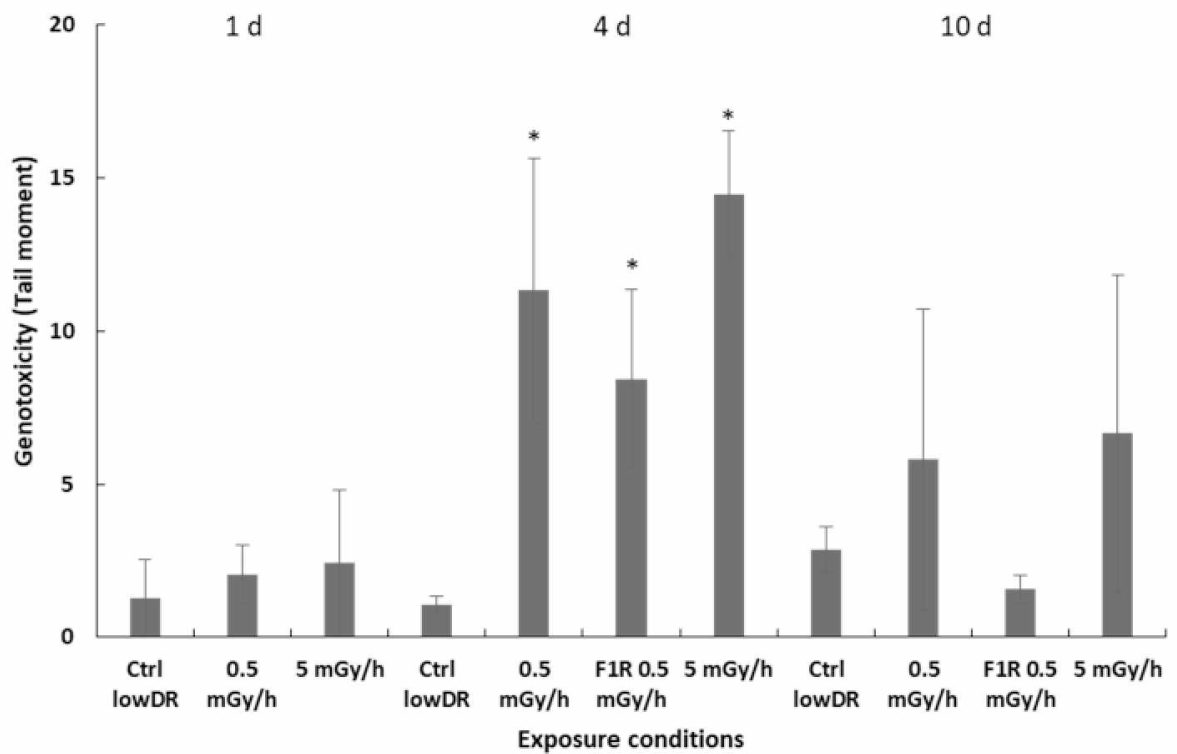

Figure 9. DNA damage (Tail moment) in the F1 progeny after 1, 4 and $10 \mathrm{~d}$ of exposure. The progeny came from adults irradiated over $24 \mathrm{~d}$ for the lowDR experiment. The progeny (3-4 hpf) were placed in irradiated and non-irradiated (F1R, Recovery) conditions. Kruskal Wallis test, Treatment versus Control *, $\mathrm{p}<0.05$. 

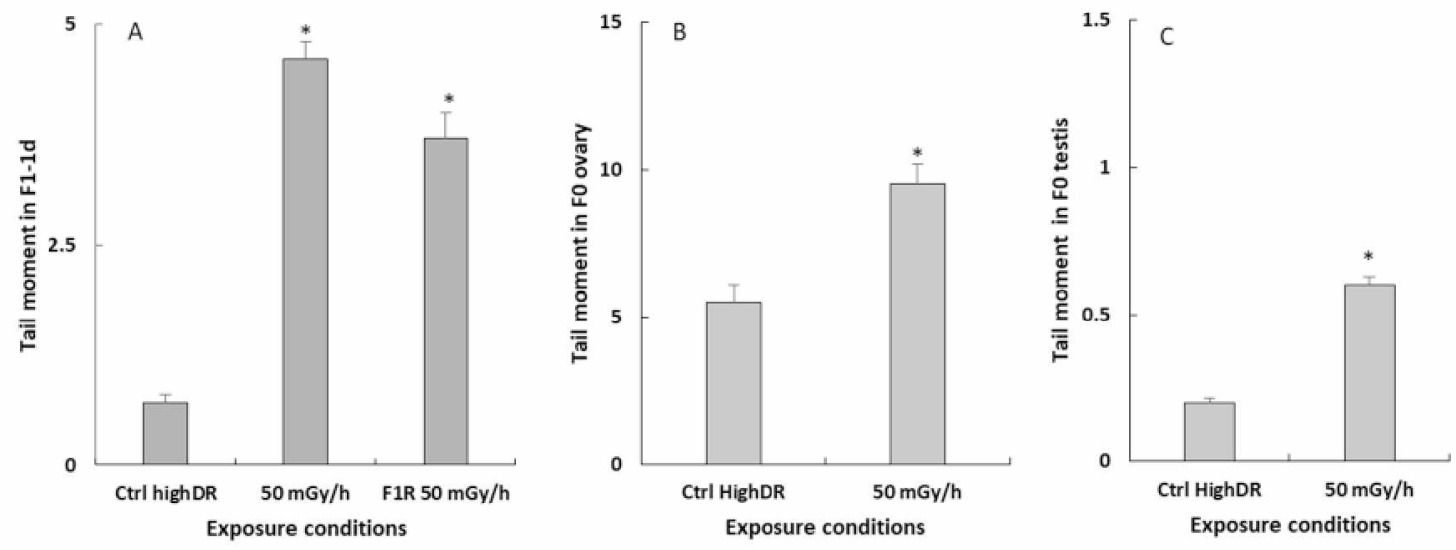

Figure 10. DNA damage (tail moment) in the progeny ( $\mathrm{A}: 1 \mathrm{~d}$, irradiated and non-irradiated exposure (F1R, Recovery)) and in gonads of FO adults (B: female, C: male) coming from the highDR experiment. Kruskal Wallis test, Treatment versus Control $*, p<0.05$. 